Article

\title{
Conjugation of Urokinase to Water-Soluble Magnetic Nanoparticles for Enhanced Thrombolysis
}

\author{
Qian Li ${ }^{1}$, Xiaojun Liu ${ }^{1}$, Zhen Lu ${ }^{2}$, Wenjun Yang ${ }^{1}$, Zili Lei ${ }^{1}$ and Ming Chang ${ }^{3, * \mathbb{C}}$ \\ 1 The State Key Laboratory of Digital Manufacturing Equipment and Technology, Huazhong \\ University of Science and Technology, Wuhan 430074, China; Qian@hust.edu.cn (Q.L.); \\ mexj1@163.com (X.L.); wss_ywj@163.com (W.Y.); beyondeye@163.com (Z.L.) \\ 2 College of Computer Science and Technology, Shanghai University of Electric Power, Shanghai 200090, \\ China; luzhen89@163.com \\ 3 Department of Mechanical Engineering, Chung Yuan Christian University, Chung Li 32023, Taiwan \\ * Correspondence: ming@cycu.edu.tw; Tel.: +886-3-2654303
}

Received: 30 September 2019; Accepted: 8 November 2019; Published: 13 November 2019

\begin{abstract}
In this study, covalent conjugation of thrombolytic drug urokinase to water-soluble magnetic nanoparticles (NPs) is proposed to enhance the efficiency of thrombolysis. Hydrophobic NPs of oleic acid (OA)-coated $\mathrm{Fe}_{3} \mathrm{O}_{4}$ are first synthesized and then surface-modified with the amphipathic copolymer poly (maleic anhydride-alt-1-octadecylene) (PMAO) to form water-soluble NPs of PMAO-OA- $-\mathrm{Fe}_{3} \mathrm{O}_{4}$ with monodispersed sizes. PMAO-OA- $\mathrm{Fe}_{3} \mathrm{O}_{4}$ NPs display a good water-based stability without aggregation at near neutral $\mathrm{pH}$ and show good magnetic separation characteristics. The thrombolytic drug urokinase is then covalently linked with the former product through dehydration condensation reaction between the amino and carboxyl produced by dehydration of the anhydride under $N$-Ethyl- $N^{\prime}$-(3-dimethylaminopropyl) carbodiimide (EDC) and $\mathrm{N}$-hydroxysuccinimide (NHS). Transmission electron microscope (TEM) images and dynamic light scattering (DLS) results show that the urokinase@PMAO-OA- $\mathrm{Fe}_{3} \mathrm{O}_{4} \mathrm{NPs}$ are uniformly dispersed in water. The in vitro thrombolytic effect based on the manipulation of magnetic coupling, combined with static and alternating current (AC) magnetic fields, in a mimic blood-vascular system was studied. Drug release test shows that AC magnetic field can be used as switch and accelerator for NPs to release drugs. In addition, thrombolytic efficiency is nearly four times that of pure urokinase. This indicates that the coupling magnetic field may be a promising method to improve thrombolytic effect of the prepared magnetic carrier drug conjugates.
\end{abstract}

Keywords: thrombolysis; urokinase; $\mathrm{PMAO}-\mathrm{OA}-\mathrm{Fe}_{3} \mathrm{O}_{4}$ nanoparticles; coupling magnetic field

\section{Introduction}

Thrombosis is a serious disease that threatens the lives of people all over the world [1]. Although research on rapid thrombolysis has progressed in recent decades [2,3], the treatment of possible hemorrhage by using large dosage of thrombolytic drugs (e.g., urokinase and streptokinase) continues to greatly restrict the improvement of medical care $[4,5]$. It remains an urgent task to develop new technologies for the treatment of such a complicated disease and relieve the discomfort of patients [6,7]. Nanomaterials are considered an emerging trend with future prospects in biomedical applications because of their possible enhanced physical, chemical, and biological functionality owing to high surface-to-volume ratios and surface charges [8]. Recently, magnetic nanoparticles (NPs) have gained significant attentions for their applications in magnetic resonance image (MRI) $[9,10]$, cell separation [11,12], and gene therapy [13]. Magnetic NPs have also been used as drug carriers for targeting therapies, such as cancer [14,15], cardiovascular diseases [16], and infectious diseases [17]. 
Magnetic carrier drugs can be guided to accumulate at specific sites under the action of external magnetic field to improve the drug concentration at the lesion locations and reduce the adverse side effects on the normal parts. However, two risk factors, hidden within these drug delivery methods for cardiovascular diseases, such as thrombotic diseases [18-20], deter expectation for clinical use. One is the possible toxicity introduced by chemicals that may damage endothelial tissue and cells [21,22]; the other is the micron scale of particles that may form new blockages in certain capillaries [23,24]. In this study, a new synthesis of a nanoscale magnetic drug that has good biocompatibility and low cytotoxicity is proposed for targeted therapy of thrombus. The magnetic carrier drug can be guided by magnetic field for rapid thrombolysis and controlled by oscillating magnetic field for drug release.

Efforts have been made to improve the thrombolytic efficiency by binding thrombolytic drug to the surface of magnetite NPs [18,25-28]. In these studies, only a static magnetic field is introduced to guide and accumulate the urokinase-coated NPs for targeted thrombolysis. In our novel, magnetic carrier drug delivery system, $\mathrm{Fe}_{3} \mathrm{O}_{4}$ NPs are first prepared with an oleic acid (OA) coating to form a hydrophobic surface. Amphipathic copolymer poly (maleic anhydride-alt-1-octadecylene) (PMAO) is then chemically bonded to OA- $-\mathrm{Fe}_{3} \mathrm{O}_{4}$ NPs to provide carboxyl groups, and the hydrophobic surface of OA-coated NPs is transformed into hydrophilic characterization. Next, urokinase is covalently bound to the magnetic NPs modified by PMAO under the action of $N$-Ethyl- $N^{\prime}$-(3-dimethylaminopropyl) carbodiimide (EDC) and $\mathrm{N}$-hydroxysuccinimide (NHS). In consideration of the therapeutic function of magnetic carriers in treating thrombosis, the presence of PMAO is considered to be an advantage for providing a large number of carboxyl groups for drug loading. In addition, nano-drugs can effectively release urokinase under the action of alternating magnetic field, which is helpful to improve thrombolytic efficiency. The prepared urokinase@PMAO-OA- $\mathrm{Fe}_{3} \mathrm{O}_{4}$ NPs are very stable in maintaining the protein drug urokinase on carriers. In vitro thrombolysis experiments show that the thrombolysis efficiency of urokinase@PMAO-OA- $\mathrm{Fe}_{3} \mathrm{O}_{4} \mathrm{NPs}$ can be increased to about four times of pure urokinase by using the coupling magnetic field composed of static magnetic field and alternating magnetic field. This indicates that effective thrombolytic effect can be achieved even if the proposed magnetic carrier is used at a lower dose. Therefore, the application of magnetically controlled urokinase@PMAO-OA- $\mathrm{Fe}_{3} \mathrm{O}_{4} \mathrm{NPs}$ is expected to be a solution for the treatment of thrombotic diseases in the future.

\section{Materials and Methods}

\subsection{Chemicals}

Ferric acetylacetonate (98\%), 1,12-Dodecanediol (98\%), oleic acid (AR), oleylamine (80-90\%), benzyl ether $(97 \%)$, and urokinase $(12,000 \mathrm{IU} / \mathrm{mg}$ ) were purchased from Macklin, Shanghai, China. EDC (97\%), NHS (97\%), and PMAO were provided by J\&K Scientific Ltd., Beijing, China.

\subsection{Synthesis of Urokinase@PMAO-OA- $\mathrm{Fe}_{3} \mathrm{O}_{4} \mathrm{NPs}$}

The synthesis process of urokinase@PMAO-OA- $\mathrm{Fe}_{3} \mathrm{O}_{4} \mathrm{NPs}$ is shown in Figure 1. Firstly, $\mathrm{OA}-\mathrm{Fe}_{3} \mathrm{O}_{4}$ NPs were synthesized by referring to Sun and Zeng's method [29]. Quantities of $0.706 \mathrm{~g}$ ferric acetylacetonate, $2.023 \mathrm{~g}$ of 1,12-Dodecanediol, $1.607 \mathrm{~g}$ of oleic acid, $1.696 \mathrm{~g}$ of oleylamine, and $20 \mathrm{~mL}$ of benzyl ether were mixed in a 50-mL three-necked flask. The mixture was heated to $200{ }^{\circ} \mathrm{C}$ with magnetic stirring for $30 \mathrm{~min}$. The heating temperature was then raised to $298^{\circ} \mathrm{C}$ for another $30 \mathrm{~min}$. After the reaction, black precipitates could be seen at the bottom of the flask; the precipitates were separated from the brown-yellow reaction liquid by attracting them with an $\mathrm{NdFeB}$ permanent magnet. The prepared product was then repeatedly washed with ethanol five to seven times and stored in hexane. 


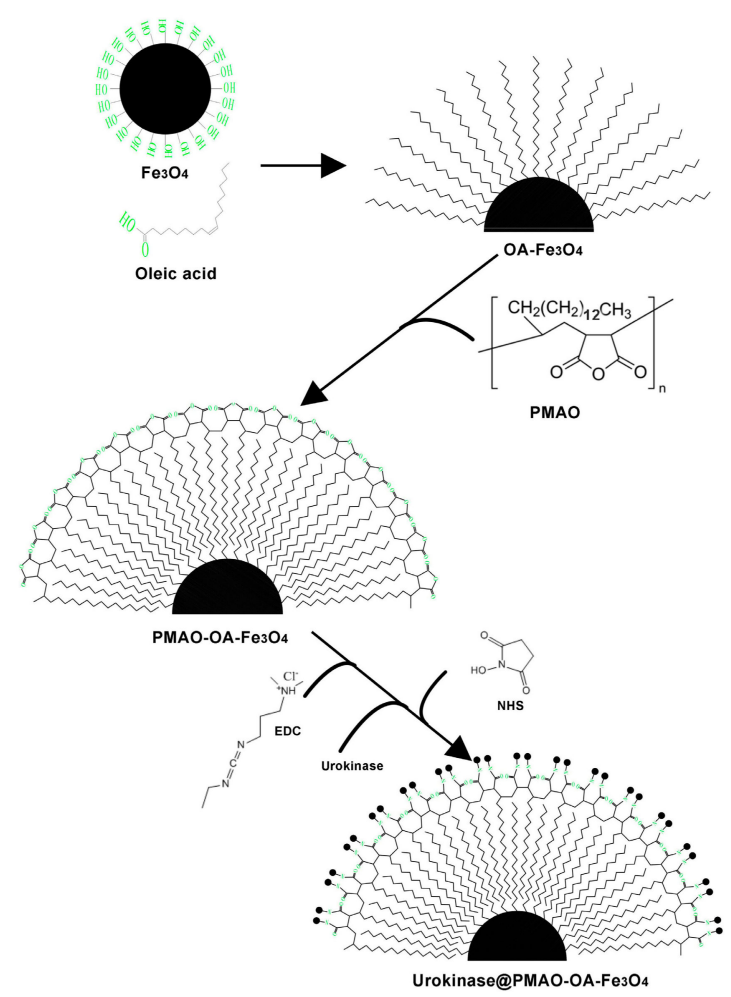

Figure 1. Schematic of synthesis process of urokinase@poly(maleic anhydride-alt-1-octadecylene) (PMAO)-oleic acid (OA)- $\mathrm{Fe}_{3} \mathrm{O}_{4}$ Nanoparticles (NPs) conjugate.

Next, $18.7 \mathrm{~g}$ of PMAO was weighed and dissolved in hexane. The solutions of previously prepared NPs and PMAO were mixed and stirred with a magnetic stirrer at room temperature for $120 \mathrm{~min}$. After evaporation of the solvent, $1.15 \mathrm{~g}$ of bis (6-aminohexyl) amine in hexane were added and sonicated for $30 \mathrm{~min}$. Then, the solvent was evaporated again to obtain a black solid product. Subsequently, the product was put into water and sonicated for another $30 \mathrm{~min}$ until the product was completely dissolved. After placing for another $2 \mathrm{~h}$, the supernatant was separated and collected in a container. To obtain dried products, the solution can be evaporated again, from which black $\mathrm{PMAO}-\mathrm{OA}-\mathrm{Fe}_{3} \mathrm{O}_{4} \mathrm{NPs}$ can be collected from the bottom of the container.

Finally, urokinase was coated on PMAO-OA- $\mathrm{Fe}_{3} \mathrm{O}_{4}$ NPs with slight modification according to the method described by Be et al. [18]. EDC and NHS with a molar ratio of 1.5:1 were first mixed in $0.1 \mathrm{M}$ PBS buffer solution. The $\mathrm{pH}$ value of the solution was adjusted to neutral by adding $\mathrm{NaOH}$ solution. After the solution was prepared, $1 \mathrm{mg}$ of PMAO-OA-Fe $\mathrm{O}_{4} \mathrm{NPs}$ and $1 \mathrm{mg}$ urokinase were added to react for $24 \mathrm{~h}$ until the urokinase coating was formed. The urokinase coated product was rinsed with distilled water to remove the unreacted materials and then dried at room temperature.

\subsection{Characterization of Magnetic Nanoparticles (NPs)}

The morphology of magnetic NPs was observed by transmission electron microscope (TEM) (JOEL JEM-2010, JOEL, Tokyo, Japan). Figure 2a,b are the TEM micrographs of PMAO-OA-Fe ${ }_{3} \mathrm{O}_{4} \mathrm{NPs}$ and urokinase-coated PMAO-OA- $\mathrm{Fe}_{3} \mathrm{O}_{4} \mathrm{NPs}$, respectively. Neither micrograph shows much aggregation. The magnetization of the NPs was evaluated by a vibrating sample magnetometer (VSM) (JDM-13, Jilin University, Jilin, China) by changing the applied magnetic field from $-150 \mathrm{kA} / \mathrm{m}$ to $150 \mathrm{kA} / \mathrm{m}$ at room temperature. The magnetization curve shown in Figure $2 \mathrm{c}$ indicates that the coercivity and remanence of $\mathrm{OA}-\mathrm{Fe}_{3} \mathrm{O}_{4} \mathrm{NPs}$, PMAO-OA- $\mathrm{Fe}_{3} \mathrm{O}_{4} \mathrm{NPs}$, and urokinase@PMAO-OA- $\mathrm{Fe}_{3} \mathrm{O}_{4}$ are all zero. The saturation magnetization of $\mathrm{OA}-\mathrm{Fe}_{3} \mathrm{O}_{4} \mathrm{NPs}$ is $47.6 \mathrm{Am} / 2 / \mathrm{kg}$, and that of PMAO-OA-Fe $\mathrm{O}_{4} \mathrm{NPs}$ and urokinase@PMAO-OA- $\mathrm{Fe}_{3} \mathrm{O}_{4} \mathrm{NPs}$ are $40 \mathrm{Am}^{2} / \mathrm{kg}$ and $34.5 \mathrm{Am}^{2} / \mathrm{kg}$, respectively. The structure of these NPs were studied by X-ray diffraction (XRD) (X'Pert PRO, PANalytical B.V., Almelo, The Netherlands) 
at diffraction angles from $20^{\circ}$ to $80^{\circ}$. As shown in Figure 2d, the peaks at (220), (311), (400), (422), (511), and (440) with respective crystal planes at $2 \theta=30.1^{\circ}, 35.4^{\circ}, 43.1^{\circ}, 53.4^{\circ}, 57^{\circ}$, and $62.6^{\circ}$ on $\mathrm{Fe}_{3} \mathrm{O}_{4}(\mathrm{JCPDS}$ card no. 85-1436) [30] are clearly displayed in the various stages of synthesis process, indicating that $\mathrm{Fe}_{3} \mathrm{O}_{4}$ are embedded in these synthesized products. The spectra of urokinase-conjunted materials and NPs were also recorded with Fourier transform infrared spectroscopy (FTIR) (VERTEX 70, Bruker, Munich, Germany), as shown in Figure 2e. The $1710 \mathrm{~cm}^{-1}$ peak assignable to the $\mathrm{C}=\mathrm{O}$ vibration in $\mathrm{OA}$ is shifted to two new bands at 1540 and $1638 \mathrm{~cm}^{-1}$ in OA-Fe $\mathrm{O}_{3} \mathrm{NPs}$, which are the asymmetric and symmetric features of OA- $\mathrm{Fe}_{3} \mathrm{O}_{4} \mathrm{NPs}$. The $563 \mathrm{~cm}^{-1}$ peak corresponds to the vibration of $\mathrm{Fe}-\mathrm{O}$ in the crystalline lattice of $\mathrm{Fe}_{3} \mathrm{O}_{4}$. The result reveals that the surface of NPs is covered with a shell of $\mathrm{OA}$. After further conjunction, all characteristic vibrations in PMAO can be seen in PMAO-OA- $\mathrm{Fe}_{3} \mathrm{O}_{4}$ $\mathrm{NPs}$, and $563 \mathrm{~cm}^{-1}$ peak indicating the Fe-O vibration is also found. The existence of $1710 \mathrm{~cm}^{-1}$ peak both in PMAO and PMAO-OA- $\mathrm{Fe}_{3} \mathrm{O}_{4}$ NPs is due to the decomposition of anhydride and the release of the - $\mathrm{COOH}$. These results reflect that the PMAO is immobilized on the outermost layer of $\mathrm{OA}-\mathrm{Fe}_{3} \mathrm{O}_{4} \mathrm{NPs}$. The $2927 \mathrm{~cm}^{-1}$ and $2854 \mathrm{~cm}^{-1}$ assigned to the asymmetric stretch and symmetric stretch of $-\mathrm{CH}_{2}$ respectively are found in all materials except pure urokinase. In addition, $563 \mathrm{~cm}^{-1}$ (Fe-O) and $1778 \mathrm{~cm}^{-1}$ (anhydride) in PMAO-OA- $\mathrm{Fe}_{3} \mathrm{O}_{4}$ are also observed. In the FTIR spectrum of urokinase@PMAO-OA-Fe $\mathrm{O}_{4}$, three characteristic peaks of urokinase are present at $1656 \mathrm{~cm}^{-1}(\mathrm{C}=\mathrm{O})$, $1542 \mathrm{~cm}^{-1}(\mathrm{~N}-\mathrm{H})$, and $1450 \mathrm{~cm}^{-1}$ (amide band). They show that urokinase is immobilized on the surface of PMAO-OA- $\mathrm{Fe}_{3} \mathrm{O}_{4}$ NPs. To ensure that the protein-coated magnetic NPs have a good response to magnetic field in aqueous phase, the magnetic performance of PMAO-OA- $\mathrm{Fe}_{3} \mathrm{O}_{4} \mathrm{NPs}$ in physiological saline under external magnetic field was observed by an UV-vis spectrophotometer (Nanodrop 2000, Thermo Fisher, Waltham, MA, USA) at $460 \mathrm{~nm}$ wavelength. The magnetic separation property of NPs solution can be confirmed by detecting its transmittance after being subjected to external magnetic field for a certain time. Four groups of solutions were prepared, including PMAO-OA- $\mathrm{Fe}_{3} \mathrm{O}_{4} \mathrm{NPs}$ in water, PMAO-OA- $\mathrm{Fe}_{3} \mathrm{O}_{4} \mathrm{NPs}$ in physiological saline, urokinase@PMAO-OA- $\mathrm{Fe}_{3} \mathrm{O}_{4} \mathrm{NPs}$ in water, and urokinase@PMAO-OA- $\mathrm{Fe}_{3} \mathrm{O}_{4} \mathrm{NPs}$ in physiological saline, with two bottles of each sample and $5 \mathrm{~mL}$ of each bottle. One bottle of each sample was placed under the magnetic field generated by the NdFeB magnet on one side of the bottle while the other bottle was not affected by magnetic field. As shown in Figure 2f, the transmittance of these solutions increases from $0 \%$ to more than $80 \%$ from 0 to 100 min under the action of magnetic field, but remains below $1 \%$ without the action of magnetic field. This shows that the prepared NPs can be easily separated by an external magnetic field. 


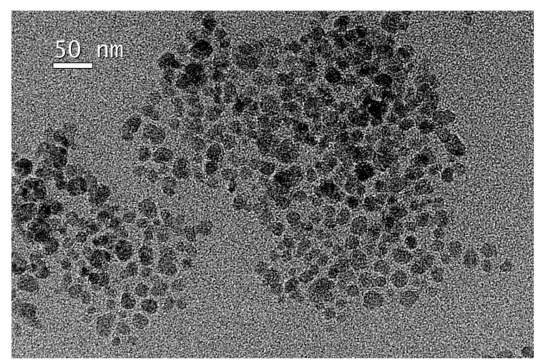

(a)

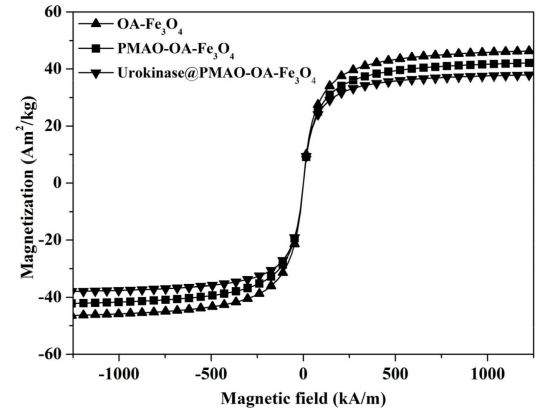

(c)

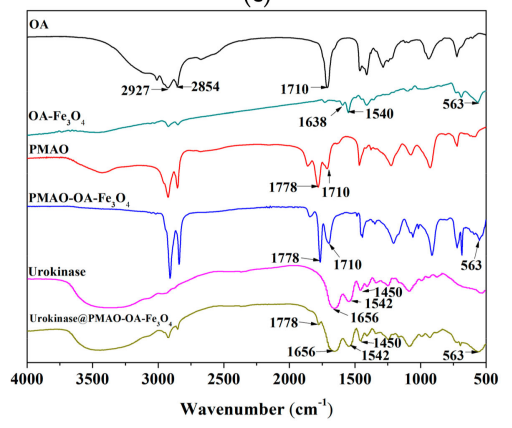

(e)

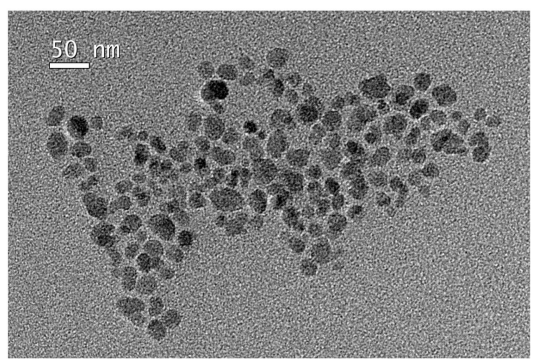

(b)

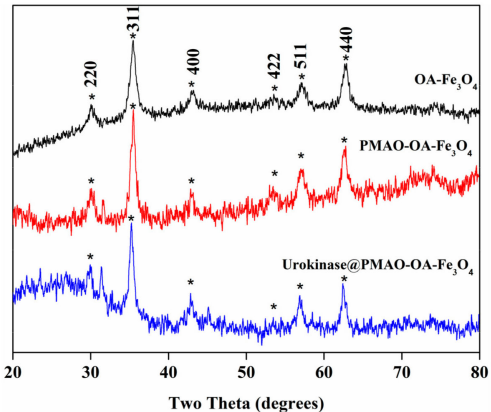

(d)

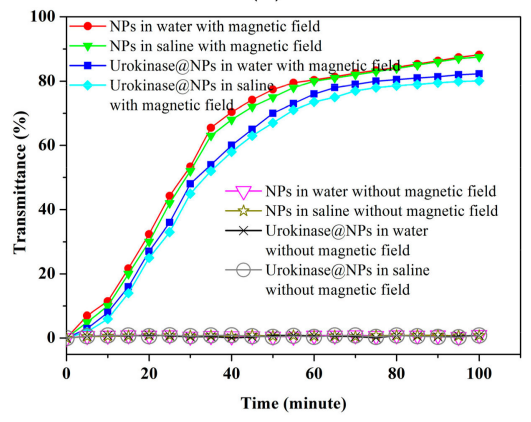

(f)

Figure 2. (a) Transmission Electron Microscope (TEM) image of PMAO-OA- $\mathrm{Fe}_{3} \mathrm{O}_{4}$ nanoparticles (NPs); (b) TEM image of urokinase@PMAO-OA- $\mathrm{Fe}_{3} \mathrm{O}_{4} \mathrm{NPs}$; (c) Field dependence of magnetization (M versus $\mathrm{H})$ plot of OA- $\mathrm{Fe}_{3} \mathrm{O}_{4} \mathrm{NPs}, \mathrm{PMAO}-\mathrm{OA}-\mathrm{Fe}_{3} \mathrm{O}_{4} \mathrm{NPs}$, and urokinase@PMAO-OA-Fe $\mathrm{O}_{4} \mathrm{NPs}$; (d) X-ray diffraction (XRD) patterns of OA- $\mathrm{Fe}_{3} \mathrm{O}_{4} \mathrm{NPs}$, PMAO-OA- $\mathrm{Fe}_{3} \mathrm{O}_{4} \mathrm{NPs}$, and urokinase@PMAO-OA-Fe $\mathrm{O}_{4}$ NPs; (e) Fourier transform infrared spectroscopy (FTIR) spectra of OA, OA-Fe $\mathrm{O}_{4} \mathrm{NPs}, \mathrm{PMAO}$, PMAO-OA- $\mathrm{Fe}_{3} \mathrm{O}_{4}$ NPs, and urokinase@PMAO-OA- $\mathrm{Fe}_{3} \mathrm{O}_{4} \mathrm{NPs}$; (f) Magnetic separation property of PMAO-OA- $\mathrm{Fe}_{3} \mathrm{O}_{4}$ NPs and urokinase@PMAO-OA- $\mathrm{Fe}_{3} \mathrm{O}_{4} \mathrm{NPs}$ in physiological saline and in water with and without an external magnetic field, as shown by the transmittance of solutions over time.

Subsequently, the colloidal stability of NPs in water and physiological saline without magnetic field was investigated with a dynamic light scattering particle size distribution analyzer (DLS) (Horiba LB-550, Horiba, Kyoto, Japan). Figure 3 displays the DLS results of NPs at the beginning of dilution and 100 min later. As shown in the figure, PMAO-OA-Fe $\mathrm{O}_{4} \mathrm{NPs}$ were dispersed in water or saline with a diameter 6-60 nm range and a mean value of $19.6 \mathrm{~nm}$; urokinase@PMAO-OA-Fe ${ }_{3} \mathrm{O}_{4} \mathrm{NPs}$ were dispersed with a diameter 8-70 $\mathrm{nm}$ range of and a mean value of $24.5 \mathrm{~nm}$, even after $100 \mathrm{~min}$. The results imply that the prepared NPs are water-soluble and stable in water and physiological saline. 

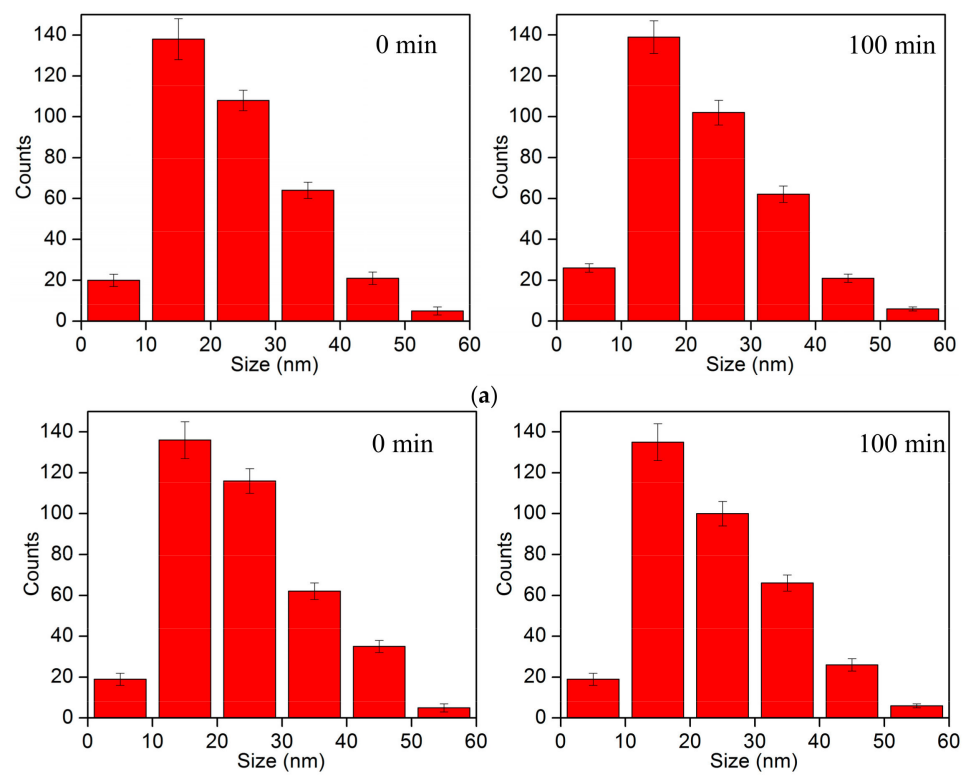

(b)
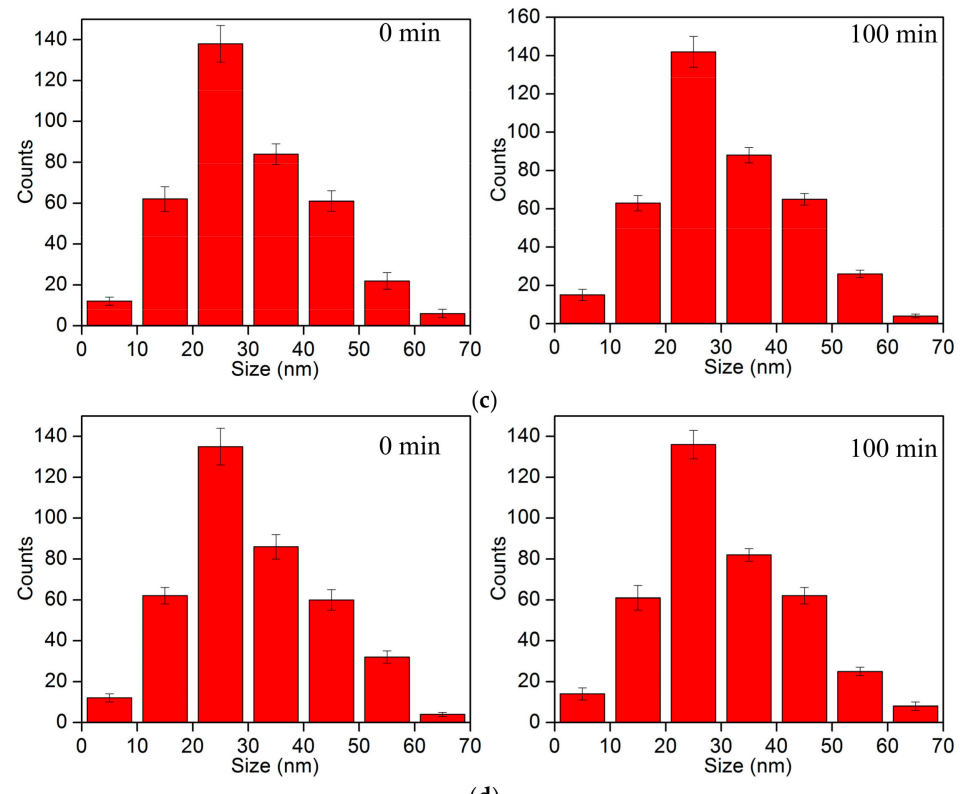

(d)

Figure 3. Size distribution of (a) $\mathrm{PMAO}-\mathrm{OA}-\mathrm{Fe}_{3} \mathrm{O}_{4} \mathrm{NPs}$ in water at the beginning of dilution and 100 min later; (b) PMAO-OA- $\mathrm{Fe}_{3} \mathrm{O}_{4}$ NPs in physiological saline at the beginning of dilution and 100 min later; (c) Urokinase@PMAO-OA- $\mathrm{Fe}_{3} \mathrm{O}_{4}$ NPs in water at the beginning of dilution and $100 \mathrm{~min}$ later; (d) Urokinase@PMAO-OA- $\mathrm{Fe}_{3} \mathrm{O}_{4} \mathrm{NPs}$ in physiological saline at the beginning of dilution and 100 min later.

\subsection{Evaluation of the Amount of Urokinase Bounding on PMAO-OA-Fe $\mathrm{O}_{4} \mathrm{NPS}$}

The amount of urokinase bound on $\mathrm{PMAO}-\mathrm{OA}-\mathrm{Fe}_{3} \mathrm{O}_{4} \mathrm{NPs}$ was determined by using Bicinchoninic Acid $\left(\mathrm{BCA}^{\mathrm{TM}}\right)$ Protein Assay Reagent Kit (P0009, Beyotime, Shanghai, China) through a multi-mode microplate reader (FlexStation3, Molecular Devices, San Jose, CA, USA). FlexStation3 can measure absorbance, fluorescence intensity, fluorescence polarization, luminescence, and time-resolved fluorescence. In this study, a calibration line was established to correlate absorbance and urokinase concentration in solution. We prepared 10 urokinase solutions, with the concentration increasing from $0.1 \mathrm{mg} / \mathrm{mL}$ to $1 \mathrm{mg} / \mathrm{mL}$ in sequence. Quantities of $200 \mu \mathrm{L}$ BCA reagent and $20 \mu \mathrm{L}$ of each solution were injected into the sample wells of the 96-well plate. Another solution in a well without urokinase was set as the control. The plate was subsequently preserved at room temperature for $2 \mathrm{~h}$. The absorbance 
of the solution in each well was detected by FlexStation 3 microplate reader at $562 \mathrm{~nm}$. Figure 4a shows that the absorbance $\mathrm{OD}_{562}$ varies linearly with urokinase concentration. Because the absorbance of the solution can be detected by FlexStation3, the concentration of urokinase in the reaction solution can be directly read by this line. The amount of urokinase attached to NPs was calculated as $D=W-C V$, where $W$ is the total amount of urokinase added in the reaction, $C$ is the measured concentration of urokinase in the supernatant after centrifugation of the NPs solution after completion of the urokinase reaction, and $V$ is the volume of the supernatant. For simplicity, the test was conducted using $1 \mathrm{mg}$ of PMAO-OA- $\mathrm{Fe}_{3} \mathrm{O}_{4}$ NPs. Figure $4 \mathrm{~b}$ shows that the obtained amount of urokinase bound to magnetic NPs varies with the amount of reactive urokinase. Experiments were repeated five times. The quantity of urokinase immobilized on the $1 \mathrm{mg}$ of magnetic NPs increased from $80 \mu \mathrm{g}$ to $756 \mu \mathrm{g}$ with the use of urokinase from $0.1 \mathrm{mg}$ to $0.8 \mathrm{mg}$; it then appears saturated and does not increase even if more urokinase is used. Therefore, the maximum dose of synthetic product $(756 \mu \mathrm{g}$ of urokinase coated on $1 \mathrm{mg}$ of $\mathrm{PMAO}-\mathrm{OA}-\mathrm{Fe}_{3} \mathrm{O}_{4} \mathrm{NPs}$ ) was used in subsequent experiments.

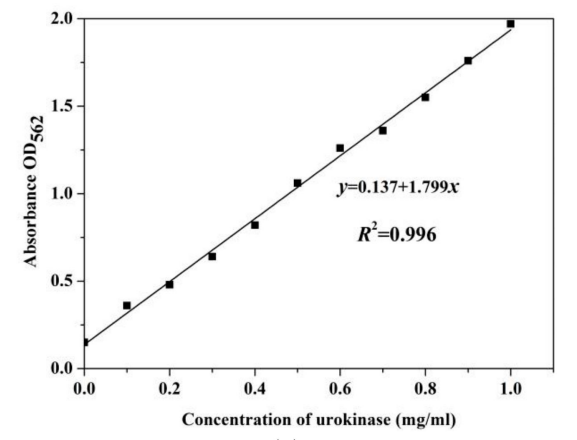

(a)

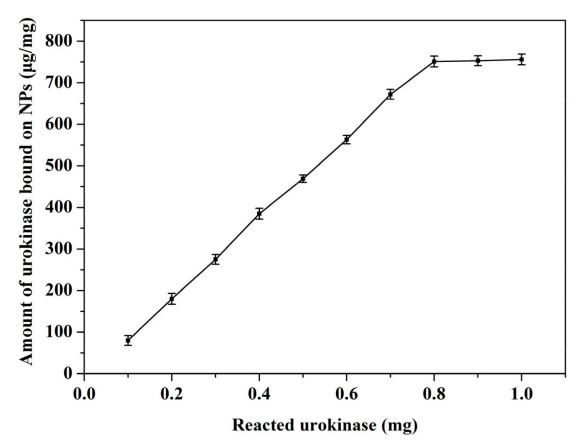

(b)

Figure 4. (a) Relationship between absorbance measured by FlexStation 3 and urokinase concentration in solution; (b) Relationship between the amount of urokinase bound to $1 \mathrm{mg}$ PMAO-OA- $\mathrm{Fe}_{3} \mathrm{O}_{4} \mathrm{NPs}$ and the amount of urokinase added to the solution.

\subsection{Toxicity Assay of Urokinase@PMAO-OA-Fe ${ }_{3} \mathrm{O}_{4} \mathrm{NPs}$}

The toxicity of magnetic NPs was evaluated by Neutral Red Cell Proliferation and Cytotoxicology Assay Kit (C0013, Beyotime, Shanghai, China). Before toxicity assay, 5000 human endothelial cells (C6246, Beyotime, Shanghai, China) were seeded into each well of 96-well plate with $200 \mu \mathrm{L}$ of cell culture solution for $2 \mathrm{~h}$. Then, the urokinase@PMAO-OA- $\mathrm{Fe}_{3} \mathrm{O}_{4}$ NPs solutions with several different concentrations were respectively added into each well of the plate. After $72 \mathrm{~h}$ of cultivation, $200 \mu \mathrm{L}$ of cell culture solution and $20 \mu \mathrm{L}$ of neutral red dye were sequentially injected into the wells. Next, the plate was placed in a shaking incubator (HZQ-QB, Suzhou Weier Experiment Equipments Co., LTD., Suzhou, China) at room temperature for $2 \mathrm{~h}$. The absorbance of each well was read using the microplate reader FlexStation 3 at $690 \mathrm{~nm}$. The culture solution without magnetic NPs was used as the control group. The determination of cell viability under the action of urokinase@PMAO-OA- $\mathrm{Fe}_{3} \mathrm{O}_{4}$ NPs can be measured by the absorbance ratio between the test solutions and the control solution. Each experiment was repeated five times. Figure 5 shows the measurement result indicating that, even if the concentration of the urokinase@PMAO-OA- $\mathrm{Fe}_{3} \mathrm{O}_{4} \mathrm{NP}$ reaches $1.2 \mathrm{mg} / \mathrm{mL}$, the cells still maintain more than $93 \%$ viability. This indicates that the prepared drug-loaded magnetic NPs have good biocompatibility, low cytotoxicity, and have good in vivo application prospects. In addition, concentration-dependent cell death was observed in the figure. This may be attributed to the mechanism that the oxidative stress related to the concentration of the iron oxide nanoparticles induces the cell injury and death [31]. However, in consideration of the shortage of the preliminary cell samples, more cell samples and technical evaluation means are needed to eliminate the possibility of misleading the event results. 


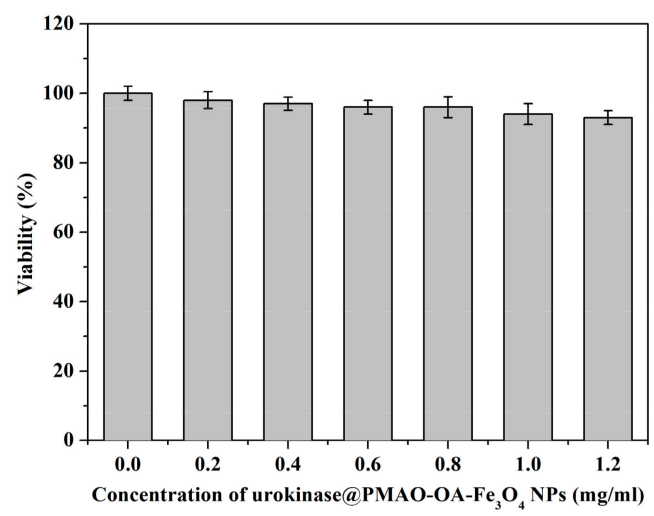

Figure 5. Assay of cell activity under the action of urokinase@PMAO-OA- $\mathrm{Fe}_{3} \mathrm{O}_{4} \mathrm{NPs}$.

\subsection{In Vitro Thrombolysis Experimental System}

The thrombolysis experiment in vitro was launched in a mimic blood vascular vessel, as shown in Figure 6a. In this system, a plastic tube with an inner diameter of $2 \mathrm{~mm}$ is regarded as the mimic blood vessel. The blood sample is collected from a healthy white mouse provided by Tongji Hospital, Wuhan, China. The blood was collected and conserved in a plastic test tube at room temperature for $2 \mathrm{~h}$, which naturally forms thrombus at the bottom of the tube. The thrombus was placed in close proximity to a semi-circular plastic fixture block glued on the vessel wall to eliminate the possibility of being flushed away by the flowing fluid. The semi-circular segmented block has the same diameter as the vessel and a thickness of $5 \mathrm{~mm}$. The thrombus was surrounded by a three-axis magnetic control system. During thrombolysis experiment, the prepared magnetic NPs solution in a $50 \mathrm{~mL}$ syringe was gradually injected into the vessel by using a micro-injection pump with an injection rate of $250 \mu \mathrm{L} / \mathrm{min}$. The final reaction solution was collected in a $500 \mathrm{~mL}$ retrieval beaker. Figure $6 \mathrm{~b}$ shows a detailed magnetic control system composed of three pairs of magnetic coils for generating a coupled magnetic field. Magnetic coils are all manually wound with the same 400 turns. The coils have an iron core on the $y$-axis, which is affected by direct current (DC) and generates a static magnetic field that magnetizes and accumulates magnetic NPs in the thrombus region. Coils on the $x$-axis and $z$-axis are input into alternating current (AC) with a phase difference of 90 degrees to generate a rotating magnetic field $(0.05 \mathrm{~T})$, forcing the NPs to rotate. The rotation would lead to rapid release of urokinase from NPs, which would further improve the thrombolysis efficiency.

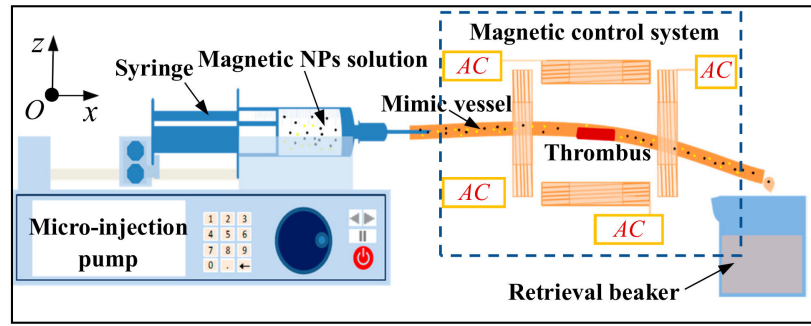

(a)

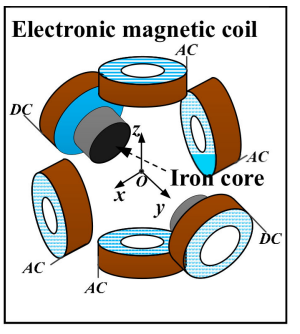

(b)

Figure 6. (a) Mimic blood vascular system for thrombolytic experiments in vitro; (b) Schematic of the three-axis magnetic control system.

\subsection{Statistical Analysis}

Each experiment in this study was repeated five times. The data were presented as mean \pm standard deviation $(n=5)$. All experimental results obtained from different treatments were analyzed by the ANOVA with the significant $p$-value $(<0.05)$ using Excel software. 


\section{Results and Discussions of Thrombolysis Experiment In Vitro}

\subsection{Drug Release Experiment}

A triggerable drug delivery system has been developed to control the release of urokinase as required, which can enhance therapeutic effect. According to the same approach as Section 2.4, the microplate reader FlexStation3 was used to evaluate the effect of alternating magnetic fields on urokinase release from the drug-loaded NPs. The regent kit containing the solution of urokinase@PMAO-OA-Fe $\mathrm{O}_{4}$ NPs $\left(756 \mu \mathrm{g}\right.$ urokinase coated on $1 \mathrm{mg}$ PMAO-OA-Fe $\left.\mathrm{O}_{4} \mathrm{NPs}\right)$ was placed in the working area of the magnetic control system, and the alternating magnetic fields of different frequencies generated by the cores on the $\mathrm{x}$-axis and $\mathrm{z}$-axis were applied to the regent kit for several minutes. The drug concentration released in the solution can be determined according to the calibration line shown in Figure $4 \mathrm{a}$ and the absorbance of the solution measured by FlexStation3. The release amount of urokinase can be obtained by $C V$, where $C$ is the measured concentration of urokinase in the supernatant after centrifugation of the NPs solution and $V$ is the volume of the supernatant.

The experiment was performed with $1 \mathrm{mg}$ PMAO-OA- $\mathrm{Fe}_{3} \mathrm{O}_{4} \mathrm{NPs}$. Figure 7 shows the drug release of urokinase@PMAO-OA- $\mathrm{Fe}_{3} \mathrm{O}_{4}$ NPs over time under the action of AC magnetic field with frequencies of $50 \mathrm{~Hz}$ and $100 \mathrm{~Hz}$ and in the absence of AC magnetic field. As shown in the figure, in the absence of AC magnetic field, the release of urokinase is only about $56 \mu \mathrm{g}$ after $60 \mathrm{~min}$. After this time, $92.6 \%$ of the initial amount of urokinase remained bound to NPs. This indicates that the prepared urokinase coated magnetic NPs are very stable and are expected to reduce the influence on non-targeted areas in long-distance transmission. While under $50 \mathrm{~Hz}$ and $100 \mathrm{~Hz}$ AC magnetic fields, the total release of urokinase includes magnetic triggering and non-magnetic triggering, which increase with time and reach $310 \mu \mathrm{g}$ and $391 \mu \mathrm{g}$, respectively, within $60 \mathrm{~min}$. Therefore, urokinase released in the presence of an alternating magnetic field is much larger than urokinase released in the absence of an alternating magnetic field. This indicates that the AC magnetic field can not only trigger and accelerate drug release, but also act as a switch for the release of the protein drug. The tentative explanation for the mechanism of drug magnetic release may be that the oscillation of magnetic NPs under alternating magnetic field would induce the breakage of the amide bond which acts as a linkage of urokinase and NPs [32].

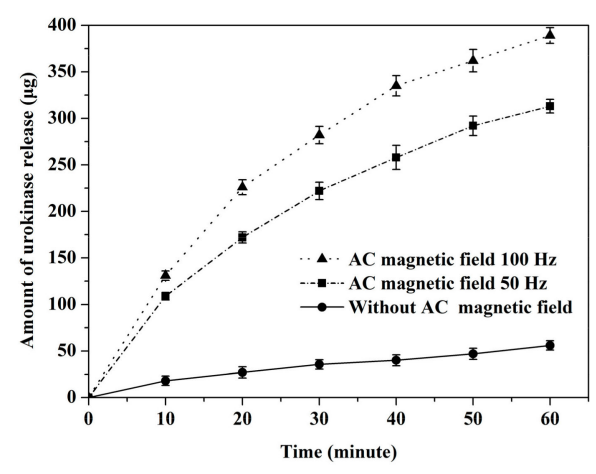

Figure 7. Effect of alternating magnetic field on triggering urokinase release.

\subsection{Thrombolysis Experiment In Vitro}

Before the mimic blood vascular vessel experiment, thrombolysis induced by the prepared urokinase@PMAO-OA- $\mathrm{Fe}_{3} \mathrm{O}_{4}$ NPs outside the magnetic control system was first observed. Four test tubes were prepared and each tube was inserted with $3 \mathrm{~mL}$ of saline and $3 \mathrm{mg}$ of thrombus. Then, three of the tubes were respectively added into pure PMAO-OA- $\mathrm{Fe}_{3} \mathrm{O}_{4}$ magnetic NPs, pure urokinase and urokinase coated magnetic NPs, at $3 \mathrm{mg}$ each. A NdFeB magnet was placed under the tubes to attract the magnetic NPs to the surface of the thrombus at the bottom. Within 90 min, the color state 
of the solution was recorded with a camera (EOS 80D, Canon, Tokyo, Japan); the image was then converted to gray scale. The more thrombus dissolved in the solution, the darker the color and the lower the gray scale. Because the maximum gray level in the image channel is 255 , the normalized gray level of the solution over time can be obtained by dividing the gray scale by 255 , as shown in Figure 8. The red color in the test tubes gradually changed from light to deep within 90 min; accordingly, the gray level also changed from high to low. The results display that the thrombus in tube containing pure physiological saline or pure PMAO-OA- $\mathrm{Fe}_{3} \mathrm{O}_{4} \mathrm{NPs}$ solution did not change much, the thrombus in pure urokinase solution decreased partially, and the thrombus in the tube of urokinase@PMAO-OA-Fe $\mathrm{O}_{4} \mathrm{NPs}$ solution almost completely dissolved. Therefore, the thrombolysis speed in urokinase@PMAO-OA-Fe ${ }_{3} \mathrm{O}$ NPs solution is obviously the fastest. This may be because the static magnetic field helps to increase the concentration of urokinase on the thrombus surface and improve thrombolytic efficiency. The prepared urokinase@PMAO-OA-Fe $\mathrm{O}_{4} \mathrm{NPs}$ can directly dissolve thrombus regardless of whether urokinase is released from the NPs.

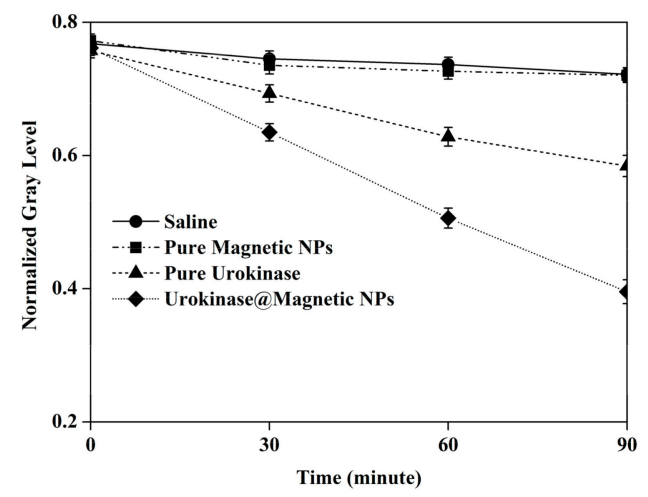

Figure 8. Comparison of thrombolysis in physiological saline, pure PMAO-OA- $\mathrm{Fe}_{3} \mathrm{O}_{4} \mathrm{NPs}$ solution, pure urokinase solution, and urokinase@PMAO-OA- $\mathrm{Fe}_{3} \mathrm{O}_{4} \mathrm{NPs}$ solution under static magnetic field generated by a $\mathrm{NdFeB}$ magnet for $90 \mathrm{~min}$.

Subsequently, thrombolysis in vitro was performed in the mimic blood-vascular system shown in Figure 6. In each experiment, $30 \mathrm{mg}$ of thrombus was placed in the working area of the magnetic control system inside the plastic tube. Then, the solutions including physiological saline, $1 \mathrm{mg} / \mathrm{mL}$ pure urokinase, $0.7 \mathrm{mg} / \mathrm{mL}$ urokinase@PMAO-OA- $\mathrm{Fe}_{3} \mathrm{O}_{4} \mathrm{NPs}$, and $1 \mathrm{mg} / \mathrm{mL}$ urokinase@PMAO-OA- $\mathrm{Fe}_{3} \mathrm{O}_{4}$ NPs were inserted into the tube respectively through the micro-injection pump. Saline experiment without urokinase or magnetic NPs was conducted as control. During the experiment, by inputting 2 ampere DC into the y-axis electromagnetic coil, a static magnetic field was introduced to accumulate the flowing nano-drug into the thrombus region. Meanwhile, a rotating magnetic field was applied by activating the coils of the $\mathrm{x}$-axis and z-axis at an amplitude of 2 ampere and a frequency of $50 \mathrm{~Hz}$, which helps trigger the release of urokinase. Thrombolysis experiments in all solutions were conducted with and without the rotating magnetic field. Each experiment was repeated five times, each time lasting $90 \mathrm{~min}$. Thrombus was removed from the tube every $30 \mathrm{~min}$, and the wet weight of the thrombus was weighed by a precision micro-balance (FA1104J, Shanghai Sunny Henping Scientific Instrument Co., Shanghai, China). Figure 9 shows the variation of thrombus wet weight with time in different solutions. As shown, almost no mass change of saline treated thrombus was observed. This illustrates that, even if the flowing fluid exerts impact force, the thrombus cannot break down automatically. When thrombus was exposed in pure urokinase, the mass loss was $7 \mathrm{mg}$ $\pm 0.3 \mathrm{mg}$ after $90 \mathrm{~min}$. However, when $0.7 \mathrm{mg} / \mathrm{mL}$ urokinase@PMAO-OA- $\mathrm{Fe}_{3} \mathrm{O}_{4} \mathrm{NPs}$ and $1 \mathrm{mg} / \mathrm{mL}$ urokinase@PMAO-OA- $\mathrm{Fe}_{3} \mathrm{O}_{4} \mathrm{NPs}$ were injected, the thrombolysis amount was increased to $13 \mathrm{mg}$ $\pm 0.4 \mathrm{mg}$ and $20 \mathrm{mg} \pm 0.4 \mathrm{mg}$, respectively, after the same treatment time even without the action of AC magnetic field. This shows that the thrombolysis rate of nano-drugs is at least twice that of pure urokinase. This may be due to the accumulation of the prepared drug-loaded magnetic NPs 
at the thrombus under the guidance of the external magnetic field, resulting in an increase in drug concentration on the surface of the thrombus. When AC magnetic field is applied, the amount of thrombolysis further increases to $21 \pm 0.4 \mathrm{mg}$ and $26 \pm 0.5 \mathrm{mg}$, corresponding to $0.7 \mathrm{mg} / \mathrm{mL}$ and $1 \mathrm{mg} / \mathrm{mL}$ urokinase@PMAO-OA- $\mathrm{Fe}_{3} \mathrm{O}_{4} \mathrm{NPs}$, respectively. Accordingly, the thrombolysis efficiency is increased by approximately four times that of pure urokinase. In comparison with the results using only static magnetic field, the further increase in thrombolysis can be attributed to the rapid release of urokinase from nanoparticles on the thrombus region triggered by alternating magnetic field. As a result, the contact area between urokinase molecules and thrombus becomes larger, which helps dissolve more thrombus in the same time range.

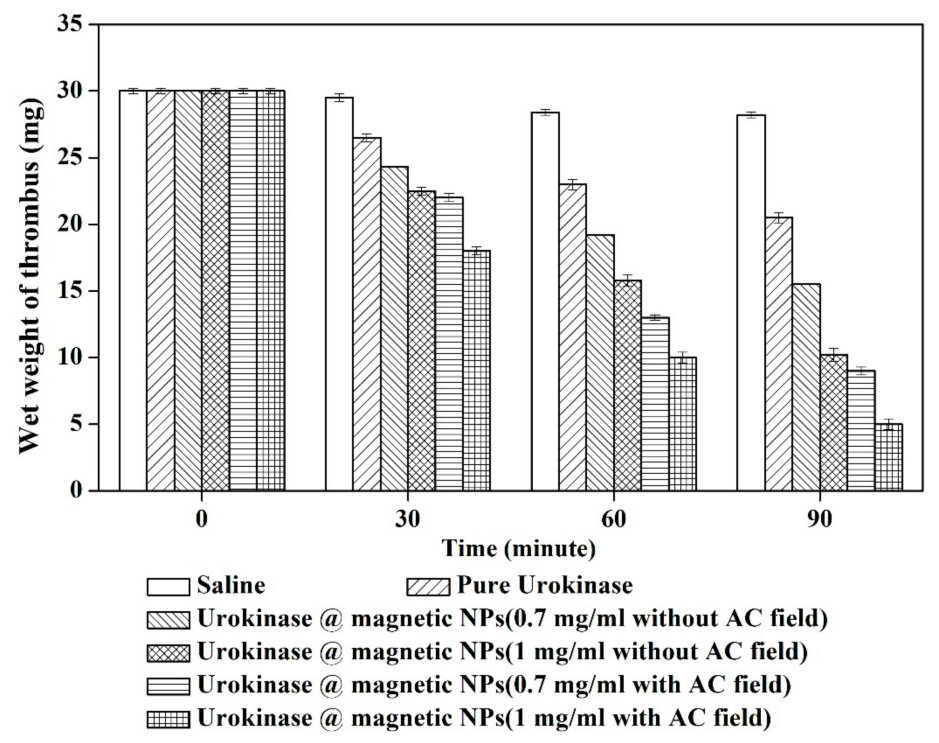

Figure 9. Comparison of wet weight of thrombus with time in solutions of saline, $1 \mathrm{mg} / \mathrm{mL}$ pure urokinase, $0.7 \mathrm{mg} / \mathrm{mL}$ urokinase@PMAO-OA- $\mathrm{Fe}_{3} \mathrm{O}_{4} \mathrm{NPs}$, and $1 \mathrm{mg} / \mathrm{mL}$ urokinase@PMAO-OA-Fe $\mathrm{O}_{4}$ NPs inside the mimic blood vascular system, wherein the nanoparticles are operated under the action of AC magnetic field with a frequency of $50 \mathrm{~Hz}$ and without AC magnetic field.

\section{Conclusions}

The synthesis and characterization of magnetic carrier drug by conjugating urokinase onto $\mathrm{PMAO}-\mathrm{OA}-\mathrm{Fe}_{3} \mathrm{O}_{4} \mathrm{NPs}$ are discussed in detail. The drug carrier of water-soluble PMAO-OA- $\mathrm{Fe}_{3} \mathrm{O}_{4}$ particle was first prepared into nano-scale monodisperse, and then successfully covalently bound with urokinase for thrombolysis. In vitro experiments show that alternating magnetic field can trigger urokinase@PMAO-OA- $\mathrm{Fe}_{3} \mathrm{O}_{4} \mathrm{NPs}$ to release drugs. Under the action of static magnetic field, the thrombolytic efficiency of nano-drugs can be improved by a factor of two. When a coupling magnetic field combined with static and alternating current magnetic fields is applied, the efficiency is increased by a factor of four. This indicates that, in addition to the traditional static magnetic field used for targeted thrombolysis, the use of coupled magnetic fields may be a new option to enhance thrombolysis with magnetic carrier drug NPs. In addition, toxicity assay shows that the urokinase@PMAO-OA- $\mathrm{Fe}_{3} \mathrm{O}_{4}$ NPs have good biocompatibility and low cytotoxicity. This implies that the prepared magnetic carrier NPs may be used in vivo experiments in the future. However, further studies have to be done to transition these NPs in vivo test before the clinical use for thrombolysis events.

Author Contributions: Q.L. conceived the experiments and wrote the paper; X.L. and W.Y. contributed materials preparation and analysis tools; M.C. contributed the idea and revised the manuscript; Z.L. (Zhen Lu) and Z.L. (Zili Lei) analyzed the data.

Funding: This research was funded by the State Key Laboratory of Digital Manufacturing Equipment and Technology, Huazhong University of Science and Technology. 
Acknowledgments: The authors gratefully acknowledge the support of the State Key Laboratory of Digital Manufacturing Equipment and Technology, Huazhong University of Science and Technology, China.

Conflicts of Interest: The authors declare no conflict of interest.

\section{References}

1. Wolach, O.; Sellar, R.S.; Martinod, K.; Cherpokova, D.; McConkey, M.; Chappell, R.J.; Silver, A.J.; Adams, D.; Castellano, C.A.; Schneider, R.K. Increased neutrophil extracellular trap formation promotes thrombosis in myeloproliferative neoplasms. Sci. Transl. Med. 2018, 10, eaan8292. [CrossRef] [PubMed]

2. Watson, L.; Broderick, C.; Armon, M.P. Thrombolysis for acute deep vein thrombosis. Cochrane Db. Syst. Rev. 2016, 11, CD002783. [CrossRef] [PubMed]

3. Engelberger, R.P.; Spirk, D.; Willenberg, T.; Alatri, A.; Do, D.; Baumgartner, I.; Kucher, N. Ultrasound-assisted versus conventional catheter-directed thrombolysis for acute iliofemoral deep vein thrombosis. Circ-Cardiovasc. Inte. 2015, 8, e002027.

4. Ebben, H.P.; Nederhoed, J.H.; Lely, R.J.; Meijerink, M.R.; Meijs, B.B.V.D.; Wisselink, W.; Yeung, K.K.; Hoksbergen, A.W.J. Low-dose Thrombolysis for Thromboembolic Lower Extremity Arterial Occlusions is Effective Without Major Hemorrhagic Complications. Eur. J. Vasc. Endovasc. 2014, 48, 551-558. [CrossRef] [PubMed]

5. Kikkert, W.J.; van Geloven, N.; van der Laan, M.H.; Vis, M.M.; Baan, J.; Koch, K.T.; Peters, R.J.; de Winter, R.J.; Piek, J.J.; Tijssen, J.G. The prognostic value of bleeding academic research consortium (BARC)-defined bleeding complications in ST-segment elevation myocardial infarction: A comparison with the TIMI (Thrombolysis In Myocardial Infarction), GUSTO (Global Utilization of Streptokinase and Tissue Plasminogen Activator for Occluded Coronary Arteries), and ISTH (International Society on Thrombosis and Haemostasis) bleeding classifications. J. Am. Coll. Cardiol. 2014, 63, 1866-1875. [PubMed]

6. Yang, F.Y.; Fang, S.F. Behavioural Assessment of Blood-Brain Barrier Opening Induced by Various Ultrasound Parameters. Proc. Eng. Technol. Innov. 2016, 3, 13-15.

7. Yang, F.Y.; Chang, W.Y.; Li, J.J.; Wang, H.E.; Chen, J.C.; Chang, C.W. Pharmacokinetic analysis and uptake of 18F-FBPA-Fr sfter ultrasound-induced blood-brain barrier disruption for potential enhancement of boron delivery for neutron capture therapy. J. Nucl. Med. 2014, 55, 616-621. [CrossRef]

8. Chimene, D.; Alge, D.L.; Gaharwar, A.K. Two-dimensional nanomaterials for biomedical applications: emerging trends and future prospects. Adv. Mater. 2015, 27, 7261-7284. [CrossRef]

9. Estelrich, J.; Sánchez-Martín, M.J.; Busquets, M.A. Nanoparticles in magnetic resonance imaging: From simple to dual contrast agents. Int. J. Nanomed. 2015, 10, 1727-1741.

10. Miller, M.A.; Gadde, S.; Pfirschke, C.; Engblom, C.; Sprachman, M.M.; Kohler, R.H.; Yang, K.S.; Laughney, A.M.; Wojtkiewicz, G.; Kamaly, N. Predicting therapeutic nanomedicine efficacy using a companion magnetic resonance imaging nanoparticle. Sci. Transl. Med. 2015, 7, 314ra183. [CrossRef]

11. Hejazian, M.; Li, W.; Nguyen, N. Lab on a chip for continuous-flow magnetic cell separation. Lab Chip 2015, 15, 959-970. [CrossRef] [PubMed]

12. Li, X.; Wei, J.; Aifantis, K.E.; Fan, Y.; Feng, Q.; Cui, F.Z.; Watari, F. Current investigations into magnetic nanoparticles for biomedical applications. J. Biomed. Mater. Res. A. 2016, 104, 1285-1296. [CrossRef] [PubMed]

13. Yin, P.T.; Shah, S.; Pasquale, N.J.; Garbuzenko, O.B.; Minko, T.; Lee, K. Stem cell-based gene therapy activated using magnetic hyperthermia to enhance the treatment of cancer. Biomaterials 2015, 81, 46-57. [CrossRef] [PubMed]

14. Zhou, Z.; Sun, Y.; Shen, J.; Wei, J.; Yu, C.; Kong, B.; Liu, W.; Yang, H.; Yang, S.; Wang, W. Iron/iron oxide core/shell nanoparticles for magnetic targeting MRI and near-infrared photothermal therapy. Biomaterials 2014, 35, 7470-7478. [CrossRef] [PubMed]

15. Huang, J.; Li, Y.; Orza, A.; Lu, Q.; Guo, P.; Wang, L.; Yang, L.; Mao, H. Magnetic nanoparticle facilitated drug delivery for cancer therapy with targeted and image-guided approaches. Adv. Funct. Mater. 2016, 26, 3818-3836. [CrossRef]

16. Ragelle, H.; Danhier, F.; Préat, V.; Langer, R.; Anderson, D.G. Nanoparticle-based drug delivery systems: A commercial and regulatory outlook as the field matures. Expert Opin. Drug Del. 2017, 14, 851-864. [CrossRef]

17. Torchilin, V.P. Multifunctional, stimuli-sensitive nanoparticulate systems for drug delivery. Nat. Rev. Drug Discov. 2014, 13, 813-827. [CrossRef] 
18. Bi, F.; Zhang, J.; Su, Y.; Tang, Y.; Liu, J. Chemical conjugation of urokinase to magnetic nanoparticles for targeted thrombolysis. Biomaterials. 2009, 30, 5125-5130. [CrossRef]

19. Drozdov, A.S.; Vinogradov, V.V.; Dudanov, I.P.; Vinogradov, V.V. Leach-proof magnetic thrombolytic nanoparticles and coatings of enhanced activity. Sci. Rep. UK 2016, 6, 28119. [CrossRef]

20. Chang, M.; Lin, Y.H.; Gabayno, J.L.; Li, Q.; Liu, X. Thrombolysis based on magnetically-controlled surface-functionalized $\mathrm{Fe}_{3} \mathrm{O}_{4}$ nanoparticle. Bioengineered 2017, 8, 29-35. [CrossRef]

21. Sanz, B.; Calatayud, M.P.; Torres, T.E.; Fanarraga, M.L.; Ibarra, M.R.; Goya, G.F. Magnetic hyperthermia enhances cell toxicity with respect to exogenous heating. Biomaterials 2017, 114, 62-70. [CrossRef] [PubMed]

22. Arami, H.; Khandhar, A.; Liggitt, D.; Krishnan, K.M. In vivo delivery, pharmacokinetics, biodistribution and toxicity of iron oxide nanoparticles. Chem. Soc. Rev. 2015, 44, 8576-8607. [CrossRef] [PubMed]

23. Uson, L.; Arruebo, M.; Sebastian, V.; Santamaria, J. Single phase microreactor for the continuous, high-temperature synthesis of $<4 \mathrm{Nm}$ superparamagnetic iron oxide nanoparticles. Chem. Eng. J. 2018, 340, 66-72.

24. Gabayno, J.L.F.; Liu, D.W.; Chang, M.; Lin, Y.H. Controlled manipulation of Fe3O4 nanoparticles in an oscillating magnetic field for fast ablation of microchannel occlusion. Nanoscale 2015, 7, 3947-3953. [CrossRef] [PubMed]

25. Prilepskii, A.Y.; Fakhardo, A.F.; Drozdov, A.S.; Vinogradov, V.V.; Dudanov, I.P.; Shtil, A.A.; Bel'Tyukov, P.P.; Shibeko, A.M.; Koltsova, E.M.; Nechipurenko, D.Y. Urokinase-conjugated magnetite nanoparticles as a promising drug delivery system for targeted thrombolysis: synthesis and preclinical evaluation. ACS Appl. Mater. Inter. 2018, 10, 36764-36775. [CrossRef] [PubMed]

26. Inada, Y.; Ohwada, K.; Yoshimoto, T.; Kojima, S.; Takahashi, K.; Kodera, Y.; Matsushima, A.; Saito, Y. Fibrinolysis by urokinase endowed with magnetic property. Biochem. Bioph. Res. Co. 1987, 148, 392-396. [CrossRef]

27. Ren, L.; Wang, X.; Wu, H.; Shang, B.; Wang, J. Conjugation of nattokinase and lumbrukinase with magnetic nanoparticles for the assay of their thrombolytic activities. J. Mol. Catal. B-Enzym. 2010, 62, 190-196. [CrossRef]

28. Yang, H.W.; Hua, M.Y.; Lin, K.J.; Wey, S.P.; Tsai, R.Y.; Wu, S.Y.; Lu, Y.C.; Liu, H.L.; Wu, T.; Ma, Y.H. Bioconjugation of recombinant tissue plasminogen activator to magnetic nanocarriers for targeted thrombolysis. Int. J. Nanomed. 2012, 7, 5159-5173.

29. Sun, S.; Zeng, H. Size-controlled synthesis of magnetite nanoparticles. J. Am. Chem. Soc. 2002, 124, 8204-8205. [CrossRef]

30. Hsieh, S.; Huang, B.Y.; Hsieh, S.L.; Wu, C.C.; Wu, C.H.; Lin, P.Y.; Hunag, Y.S.; Chang, C.W. Green fabrication of agar-conjugated $\mathrm{Fe}_{3} \mathrm{O}_{4}$ magnetic nanoparticles. Nanotechnology. 2010, 21, 445601. [CrossRef]

31. Naqvi, S.; Samim, M.; Abdin, M.Z.; Ahamed, F.J.; Maitra, A.N.; Prashant, C.K.; Dinda, A.K. Concentration-dependent toxicity of iron oxide nanoparticles mediated by increased oxidative stress. Int. J. Nanomed. 2010, 5, 983-989. [CrossRef] [PubMed]

32. Chen, P.; Hu, S.; Hsiao, C.; Chen, Y.; Liu, D.; Chen, S. Multifunctional magnetically removable nanogated lids of $\mathrm{Fe}_{3} \mathrm{O}_{4}$-capped mesoporous silica nanoparticles for intracellular controlled release and MR imaging. J. Mater. Chem. 2011, 21, 2535-2543. [CrossRef]

(C) 2019 by the authors. Licensee MDPI, Basel, Switzerland. This article is an open access article distributed under the terms and conditions of the Creative Commons Attribution (CC BY) license (http://creativecommons.org/licenses/by/4.0/). 